\title{
Avaliação do comportamento reológico de argamassa de revestimento por meio do ensaio de cisalhamento direto
}

\author{
Evaluation of the rheological coating mortar behavior by the direct shear test \\ Evaluación del comportamiento reológico del mortero de revestimiento mediante el ensayo de \\ cizallamiento directo
}

Recebido: 30/12/2020 | Revisado: 31/12/2020 | Aceito: 05/01/2021 | Publicado: 06/01/2021
Ingridy Ranyelli Quitéria Sales Nascimento ORCID: https://orcid.org/0000-0001-6897-8345 Universidade de Pernambuco, Brasil E-mail: ingridynas@gmail.com
Stela Fucale
ORCID: https://orcid.org/0000-0002-7536-498X Universidade de Pernambuco, Brasil E-mail: sfucale@ poli.br
Angelo Just da Costa e Silva
ORCID: https://orcid.org/0000-0002-0759-6439 Universidade de Pernambuco, Brasil E-mail: angelojust@gmail.com
Aline Cátia da Silva
ORCID: https://orcid.org/0000-0003-4664-6256 Universidade Federal de Pernambuco, Brasil E-mail: alinecatia.catia@gmail.com
Silvio Romero de Melo Ferreira ORCID: https://orcid.org/0000-0002-5760-1494
Universidade Federal de Pernambuco, Brasil E-mail: sr.mf@hotmail.com

\begin{abstract}
Resumo
O comportamento das argamassas no estado fresco tem sido objeto de diversas pesquisas recentes no Brasil. Torna-se, portanto, interessante a adoção de novas tecnologias que busquem otimizar o desempenho das argamassas, melhorando o conhecimento das suas propriedades, possibilitando uma aplicação produtiva e minimizando, sobretudo, futuras falhas. $\mathrm{O}$ artigo analisa o comportamento de argamassas de revestimento, no estado fresco, verificando a eficácia da utilização do equipamento de cisalhamento direto com diferentes combinações de traços e materiais de composição. Foram dosados quatro traços de argamassa, com proporções distintas da cal (TR1 = 1:0:6; TR2 = 1:0,5:6; TR3 = 1:1:6 - referência; TR4 = 1:1,5:6), apresentando espalhamento (flowtable) constante e igual a $245 \pm 5 \mathrm{~mm}$. Os ensaios de cisalhamento direto foram realizados aplicando diferentes tensões normais (10 kPa, $37 \mathrm{kPa}$ e $50 \mathrm{kPa})$ e velocidade cisalhante de $0,2 \mathrm{~mm} / \mathrm{min}$. O método permitiu identificar aumento das tensões cisalhantes, coesão, ângulo de atrito e deslocamentos horizontais à medida que a cal é adicionada na mistura, indicando a sensibilidade do método e grande potencial de sua utilização para essa avaliação em argamassas em estado fresco. A adição de cal ao traço eleva o fator água/cimento para uma mesma trabalhabilidade no estado fresco, mas no estado endurecido pode aumentar a porosidade das argamassas, causando perda de RCS. As eletromicrografias permitiram identificar os poros, os arranjos entre os constituintes, a rugosidade das superfícies, as zonas de interface entre materiais e os cristais presentes na pasta-ligante.
\end{abstract}

Palavras-chave: Argamassa; Estado fresco; Cisalhamento direto; Resistência à compressão simples; Microscopia eletrônica de varredura.

\begin{abstract}
The coating mortars behavior in its fresh state has been the object of many recent researches in Brazil. It has become, therefore, interesting the introduction of new technologies, which seek to optimize the performance of mortars, improving the knowledge of its properties, allowing a productive enforcement and minimizing, overall, future failures. The article analyzes the coating mortars' behavior, in its fresh state, verifying the efficiency in the use of the direct shear equipment, with different combinations of traces and composing materials. Four traces of mortar were dosed, with distinct proportions of lime (TR1 $=1: 0: 6$; TR2 $=1: 0,5: 6 ;$ TR3 $=1: 1: 6-$ reference; TR4 $=1: 1,5: 6$ ), presenting constant scattering (flowtable) and equal to $245 \pm 5 \mathrm{~mm}$. Direct shear assays were done applying different normal tensions (10 kPa, $37 \mathrm{kPa}$ and $50 \mathrm{kPa}$ ) and shear speed of $0,2 \mathrm{~mm} / \mathrm{min}$. The method allowed to identify increase of shear tensions, cohesion, friction angle and horizontal displacements as lime is added on the mixture, indicating the sensibility of the method and great potential of use to this appraisal in mortar in its fresh state. The addition of lime in
\end{abstract}


traces increases the water/cement factor for the same workability in the fresh state, but in the hardened state it can increase the porosity of mortar, causing loss of RCS. Eletromicrografhs made it possible to identify the pores, the arrangements between the constituents, the roughness of the surfaces, the interface areas between materials and the crystals present in the binder paste.

Keywords: Mortar; Fresh state; Direct shear; Resistence to simple compression; Scanning electron microscopy (SEM).

\section{Resumen}

El comportamiento de los morteros en estado fresco ha sido objeto de varios estudios recientes en Brasil. Por tanto, es interesante adoptar nuevas tecnologías que busquen optimizar el rendimiento de los morteros, mejorando el conocimiento de sus propiedades, permitiendo una aplicación productiva y minimizando, sobre todo, los fallos futuros. El artículo analiza el comportamiento de los morteros de revestimiento, en estado fresco, verificando la efectividad del uso de equipos de cizallamiento directo con diferentes combinaciones de trazos y materiales de composición. Se dosificaron cuatro trazas de mortero, con diferentes proporciones de cal (TR1 = 1:0:6; TR2 = 1:0,5:6; TR3 = 1:1:6 - referencia; TR4 = 1:1,5:6 ), con una extensión de flujo constante igual a $245 \pm 5$ mm Los ensayos de cizallamiento directo se realizaron utilizando diferentes esfuerzos normales (10 kPa, $37 \mathrm{kPa}$ y $50 \mathrm{kPa})$ y una velocidad de cizallamiento de $0,2 \mathrm{~mm} / \mathrm{min}$. El método permitió identificar mayores esfuerzos cortantes, cohesión, ángulo de fricción y desplazamientos horizontales a medida que se agrega cal a la mezcla, lo que indica la sensibilidad del método y el gran potencial de su uso para esta evaluación en morteros frescos. La adición de cal a la mezcla aumenta el factor agua/cemento para la misma trabajabilidad en estado fresco, pero en estado endurecido puede aumentar la porosidad del mortero, provocando pérdida de RCS. Las electromicrografías permitieron identificar los poros, la disposición entre los componentes, la rugosidad de las superficies, las áreas de interfaz entre los materiales y los cristales presentes en la pasta aglutinante.

Palabras clave: Mortero; Estado fresco; Cizalla directa; Resistencia a la compresión simple; Microscopía electrónica de barrido (MEB).

\section{Introdução}

As argamassas de revestimento são definidas na Engenharia Civil como materiais obtidos pela mistura, em proporções adequadas, de aglomerante (cimento e cal), agregado miúdo e água, com ou sem aditivos e adições (ABNT, 2005). O interesse em um melhor conhecimento das propriedades dos elementos constituintes, bem como uma possível inserção de novos materiais no processo produtivo, vem motivando avanços no estudo das argamassas de revestimento (Sousa, 2005; Carasek, et al., 2016; Tokarski, 2018).

As formas de aplicação das argamassas de revestimento nas obras ainda são consideradas rudimentares, o que dificulta a obtenção de resultados eficazes ao longo da vida útil das edificações (Carasek, 2010). Uma argamassa trabalhável deve apresentar facilidade de manuseio e permitir uma aplicação na qual a tensão limite alcançada propicie aderência com o substrato, evitando assim o deslizamento do material no estado fresco e o seu descolamento após o endurecimento (Sousa \& Bauer, 2002). A trabalhabilidade pode ser considerada uma propriedade subjetiva das argamassas, pois além de não existir uma condição homogênea da argamassa padrão, esse material é caracterizado pela consistência e plasticidade, favorecendo a mobilidade e coesão na área de aplicação (Santos, 2011).

$\mathrm{Na}$ análise de argamassas de revestimento no estado fresco surge como alternativa a utilização do ensaio de cisalhamento direto, aplicado, corriqueiramente, para a caracterização geotécnica de solos. Apesar dos parâmetros (coesão e ângulo de atrito) obtidos com os ensaios de cisalhamento direto não afirmarem uma trabalhabilidade das argamassas, estudos exploratórios anteriores indicam a utilização do ensaio para as argamassas no estado fresco (Sousa, 2005; Carasek, et al., 2016; Sousa \& Bauer, 2002; Lu, Wang \& Rudolphi, 2007; Lu \& Wang, 2011; Araújo, et al., 2017) e também no estado endurecido (Campos, 2014).

O uso do ensaio de cisalhamento direto em argamassas de revestimento ainda é um método pouco empregado. Dessa forma, não há uma determinada velocidade de ensaio para cada estado de argamassa, nem definição se as velocidades utilizadas no ensaio são consideradas baixas ou altas. Para Campos (2014) a velocidade de carregamento depende da coesão da amostra e deve seguir valores utilizados em ensaios anteriores realizados em outras pesquisas. A autora ainda afirma que, para 
a realização do ensaio nas argamassas em seu estado fresco, a velocidade máxima a ser aplicada ao equipamento deve ser de $1,0 \mathrm{~mm} / \mathrm{min}$.

De acordo com Almeida, et al. (2013), outro fator relevante no ensaio é a tensão normal, visto que a tensão normal utilizada na sua pesquisa se baseou no critério de que pelo menos um ponto esteja próximo a tensão normal nula, sendo esta de $10 \mathrm{kPa}$, e as demais tensões aplicadas possuam valores superiores a este, porém ainda considerados baixos, representados por $60 \mathrm{kPa}, 90 \mathrm{kPa}$ e $150 \mathrm{kPa}$. De maneira análoga, Campos (2014) sugere que as tensões normais aplicadas estejam próximas da tensão nula, devido ao fato de que o sistema de revestimento quando aplicado ao substrato, torna-se sujeito a ações de uma força normal nula. Além disso, a autora recomenda que cada amostra de traço ensaiada deva ser submetida a, no mínimo, três tensões normais distintas.

A tensão cisalhante aumenta à medida que as tensões normais crescem, sendo justificado pela maior força vertical (tensão normal $-\sigma$ ) aplicada à amostra, necessitando assim de uma maior tensão (tensão cisalhante $-\tau$ ) para que ocorra a ruptura. Os parâmetros obtidos com o ensaio de cisalhamento direto se mostram sensíveis às modificações realizadas nos traços das argamassas (Carasek, et al., 2016; Lu \& Wang, 2011; Araújo, et al., 2017; Campos, 2014; Almeida, et al., 2013; Sousa \& Aquino Filho, 2013).

Segundo Sousa (2005), o teor de aglomerante presente nas argamassas exerce uma correlação direta com o aumento da coesão. Valores de coesão acima de 8,0 kPa parecem razoáveis na caracterização de uma argamassa no estado fresco. No entanto, ainda é cedo estimar valores de referência para auxiliar em uma definição de trabalhabilidade, no caso da coesão e do ângulo de atrito interno, em virtude da escassez de estudos. Parâmetros obtidos com o ensaio de cisalhamento direto, utilizando diferentes quantidades de água nos traços ensaiados, mostraram-se sensíveis às alterações da água, chegando-se a conclusão de que a adição de água aos traços de argamassa necessita de uma menor tensão cisalhante para romper a amostra, obtendo-se menores valores para a coesão (Araújo, et al., 2017).

No Brasil, embora se tenha um avanço expressivo nos últimos anos a cerca de técnicas para avaliação do comportamento reológico de argamassas, ainda há a necessidade de estudos complementares para uma análise mais detalhada dessa propriedade (Araújo, et al., 2017).

Nesse contexto, o presente trabalho tem por objetivo analisar o comportamento de argamassas de revestimento com diferentes proporções da cal em seu estado fresco, a partir do método normatizado adaptado da D3080 (ASTM, 2011), usado na área de Geotecnia, submetidas a distintas tensões normais. Também é analisado o desempenho das argamassas no estado endurecido, por meio dos ensaios de resistência à compressão simples e da Microscopia Eletrônica de Varredura (MEV).

\section{Metodologia}

Este estudo experimental é de origem quali-quantitativa, conforme características descritas por Koche (2011), Ludke \& Andre (2013) e Pereira, et al. (2018). A pesquisa consistiu, primeiramente, da aquisição dos materiais em estabelecimentos comerciais da região, procedida de preparação e caracterização em laboratório. As argamassas de revestimento foram produzidas com um tipo de dosagem usual nas obras de construção locais, variando-se o teor de cal adicionado. Por fim, ensaios de cisalhamento direto, resistência à compressão simples e microscopia eletrônica de varredura foram executados para avaliação do comportamento das argamassas.

\subsection{Materiais}

Para a produção das argamassas foram utilizados agregados miúdos obtidos em uma empresa especializada no ramo, definidos no mercado como areias ensacadas, provenientes de jazidas localizadas em Sirinhaém/PE, e comercializados como areia fina e areia grossa, conforme NBR 7211 (ABNT, 2009b). Tais materiais passaram em laboratório pelo processo de 
secagem, utilizando-se uma estufa por $24 \mathrm{~h}$, com posterior peneiramento para utilização das frações passantes nas peneiras de 2,38 $\mathrm{mm}$ (areia grossa) e 1,19 $\mathrm{mm}$ (areia fina).

As caracterizações quanto à composição granulométrica, massa unitária, massa específica e teor de material pulverulento seguem as especificações normativas da NBR NM 248 (ABNT, 2003b), NBR NM 45 (ABNT, 2006), NBR NM 52 (ABNT, 2009a) e NBR NM 46 (ABNT, 2003a), respectivamente. As características físicas da areia fina e da areia grossa encontram-se na Figura 1 e Tabela 1.

Figura 1: Curvas granulométricas (areia fina e areia grossa).

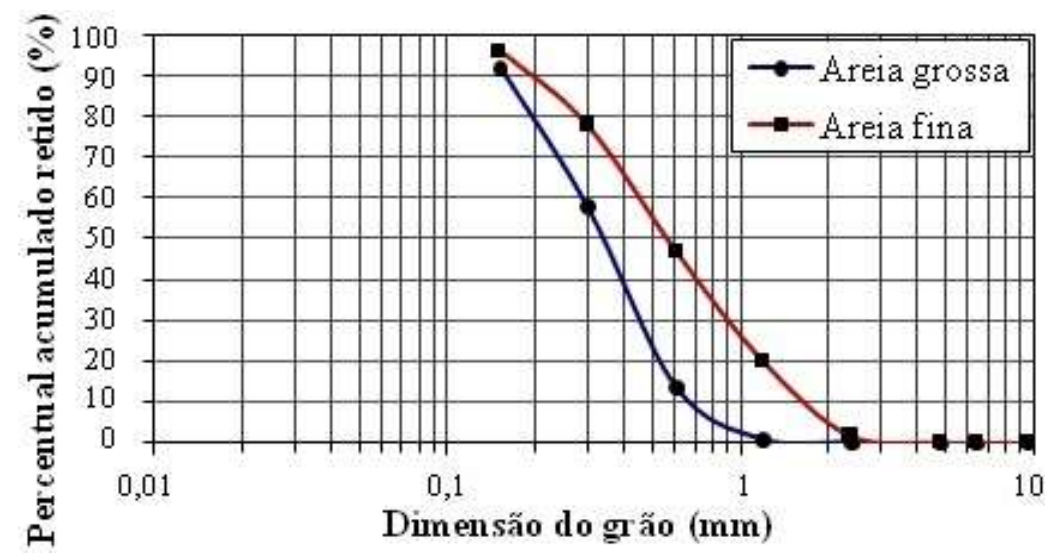

Fonte: Autores.

Tabela 1: Caracterização física dos agregados.

\begin{tabular}{|l|c|c|c|c|c|}
\hline Agregado & $\begin{array}{c}\text { Módulo de } \\
\text { Finura }\end{array}$ & $\begin{array}{c}\text { Diâmetro } \\
\text { Máximo } \\
(\mathrm{mm})\end{array}$ & $\begin{array}{c}\text { Massa } \\
\text { Unitária } \\
(\mathrm{g} / \mathrm{cm} 3)\end{array}$ & $\begin{array}{c}\text { Massa } \\
\text { Específica } \\
(\mathrm{g} / \mathrm{cm} 3)\end{array}$ & $\begin{array}{c}\text { Material } \\
\text { Pulverulento } \\
(\%)\end{array}$ \\
\hline Areia fina & 1,64 & 1,18 & 1,17 & 2,62 & 1,59 \\
\hline Areia grossa & 2,43 & 4,80 & 1,28 & 2,66 & 0,94 \\
\hline
\end{tabular}

Fonte: Autores.

As areias são uniformes e bem graduadas, segundo a NBR 7211 (ABNT, 2009b), visto que o coeficiente de uniformidade é menor do que 5. Os valores de massa específica são $2,62 \mathrm{~g} / \mathrm{cm}^{3}$ (areia fina) e 2,66 g/ $/ \mathrm{cm}^{3}$ (areia grossa), próximos ao encontrado por diversos autores (Sousa, 2005; Campos, 2014; Almeida, et al., 2013; Sousa \& Aquino Filho, 2013; Silva, 2011). Os teores de materiais pulverulentos são de 1,59\% (areia fina) e 0,94\% (areia grossa), semelhante ao obtido em outras pesquisas (Carasek, et al., 2016; Silva, 2011).

O cimento utilizado na dosagem das argamassas de revestimento foi o CPII Z-32, considerado o mais empregado em argamassas de revestimento, pois permite uma boa secagem e trabalhabilidade adequada a todos os tipos e fases de obra. As características físicas, químicas e mecânicas do cimento foram fornecidas pelo fabricante. Ensaios complementares foram realizados para determinação de sua massa específica (ABNT, 2001), tempo de início e fim de pega (ABNT, 2018), uma vez que o tempo entre a dosagem dos traços e o início do ensaio de cisalhamento direto é de aproximadamente 15 min.

Os dados obtidos nos ensaios de caracterização física do cimento (CPII Z-32) são apresentados na Tabela 2. Os valores de massa específica e massa unitária do cimento situam-se próximos dos valores de Sousa \& Aquino Filho (2013), que foram de $3,05 \mathrm{~g} / \mathrm{cm}^{3}$ e $0,99 \mathrm{~g} / \mathrm{cm}^{3}$, respectivamente. Os autores utilizaram o mesmo tipo de cimento deste estudo nas dosagens 
dos traços de argamassa de revestimento e os dados cedidos pelo fornecedor. Os tempos de início e fim de pega do CPII Z-32 enquadram-se dentro dos limites normativos e foram compatíveis com os valores encontrados na literatura (Carasek, et al., 2016; Almeida, et al., 2013).

A cal hidratada usada foi a CH-I para argamassas e possui selo de qualidade, segundo a Associação Brasileira de Cimento Portland (ABCP). Foram realizados ensaios de massa unitária, massa específica, retenção de água, finura, quantidade de $\mathrm{CO}_{2}$, umidade, quantidade de sílica e sólidos insolúveis, em diferentes períodos de tempo, conforme correspondentes normativas brasileiras, Tabela 3. Estes ensaios foram conduzidos para avaliar a trabalhabilidade das argamassas produzidas, visto que a qualidade da cal afeta o desempenho e a durabilidade dos revestimentos (Paiva, Gomes \& Oliveira, 2007).

A cal foi classificada como cal hidratada tipo I (CH-I) e considerada apta à comercialização, exceto pelo teor de $\mathrm{CO}_{2}$, que ultrapassou o limite normativo $(\leq 7 \%)$, Tabela 3. Teores elevados de $\mathrm{CO}_{2}$ presentes na cal podem ser justificados por falhas no processo de calcinação durante a sua fabricação ou mau armazenamento da aglomerante após sua utilização (Paiva, Gomes \& Oliveira, 2007). A umidade da cal de 0,126\% é considerada baixa, segundo os autores (Paiva, Gomes \& Oliveira, 2007), caracterizando-a como uma cal de boa qualidade.

Tabela 2: Caracterização física do cimento CPII Z-32.

\begin{tabular}{|l|l|c|c|}
\hline \multicolumn{1}{|c|}{ Método de Ensaio } & \multicolumn{1}{|c|}{ Característica Analisada } & Unidade & Valor \\
\hline NBR 16605 (ABNT, 2017) & Massa específica & $\mathrm{g} / \mathrm{cm}^{3}$ & 2,94 \\
\hline NBR NM 45 (ABNT, 2017) & Massa unitária & $\mathrm{g} / \mathrm{cm}^{3}$ & 1,54 \\
\hline NBR 16607 (ABNT, 2018) & Início de pega & $\mathrm{min}$ & 120 \\
\hline NBR 16607 (ABNT, 2018) & Fim de pega & $\mathrm{min}$ & 170 \\
\hline
\end{tabular}

Fonte: Autores.

Tabela 3: Caracterização física e química da cal CH-I.

\begin{tabular}{|c|l|c|c|c|c|c|}
\hline \multirow{2}{*}{ Método de Ensaio } & Característica Analisada & Unidade & Valor & \multicolumn{2}{|c|}{$\begin{array}{c}\text { Limites NBR 7175 } \\
\text { (ABNT, 2003d) }\end{array}$} \\
\hline \multirow{2}{*}{ NBR 16605 (ABNT, 2017) } & Massa específica & $\mathrm{g} / \mathrm{cm}^{3}$ & 1,140 & - & - & - \\
\cline { 2 - 7 } & Finura peneira $\mathrm{n}^{\circ} 0,6 \mathrm{~mm}$ & $\mathrm{~g} / \mathrm{cm}^{3}$ & 0,920 & - & - & - \\
\hline \multirow{2}{*}{ NBR 9289 (ABNT, 2000) } & Finura peneira $\mathrm{n}^{\circ} 0,075 \mathrm{~mm}$ & $\%$ & 0,010 & $\leq 0,5$ & $\leq 0,5$ & $\leq 0,5$ \\
\cline { 2 - 7 } & Anidrido Carbônico $\left(\mathrm{CO}_{2}\right)$ & $\%$ & 1,750 & $\leq 10$ & $\leq 15$ & $\leq 15$ \\
\hline \multirow{2}{*}{ NBR 6473 (ABNT, 2003c) } & Umidade & $\%$ & 16,360 & $\leq 7$ & $\leq 7$ & $\leq 15$ \\
\cline { 2 - 7 } & Finura peneira $\mathrm{n}^{\circ} 0,6 \mathrm{~mm}$ & $\%$ & 0,126 & - & - & - \\
\hline
\end{tabular}

Fonte: Autores.

\subsection{Definição dos traços e produção das argamassas}

Foram produzidos quatro traços distintos para as argamassas de revestimento, com proporções diferentes da ligante cal, denominados como TR1 (1:0:6), TR2 (1:0,5:6), TR3 (1:1:6) e TR4 (1:1,5:6), a fim de proporcionar diferentes comportamentos de trabalhabilidade à mistura e verificar a viabilidade de utilização do método de cisalhamento direto, comumente aplicado a solos, em argamassas de revestimento no estado fresco. Todos os traços foram definidos com proporções em volume e para os respectivos materiais: cimento (CP II Z-32), cal hidratada (CH-I), areia (50\% fina + 50\% grossa = agregado miúdo) e água. 
Para a preparação dos traços, primeiramente, misturou-se os aglomerantes (cal e cimento) e em seguida, adicionadas a estes as correspondentes quantidades de agregado miúdo. Na sequência, metade da quantidade de água é colocada no traço, misturando-se os materiais manualmente, proporcionando assim uma melhor homogeneidade da mistura. Posteriormente, o traço é colocado em um misturador de argamassa, realizando-se a mistura em duas velocidades distintas, primeiro na mais baixa $(\mathrm{v}=830 \mathrm{rpm})$ durante $30 \mathrm{~s}$, indicado na própria argamassadeira, e depois na mais alta $(\mathrm{v}=1680 \mathrm{rpm})$ por mais $60 \mathrm{~s} . \mathrm{O}$ restante da água do traço é colocado no momento da mistura na argamassadeira. Segundo Rubio-Hernández (2018), há um ponto de equilíbrio entre a mistura do cimento com seus aglomerantes, sendo este suficiente para quebrar todos os aglomerados de partículas, contudo limita-se pela possibilidade de provocar o efeito oposto. Cabe destacar que o padrão das misturas e a metodologia do ensaio são relevantes durante o procedimento, visto que a uniformidade de preparação do traço acarreta menor divergência aos resultados obtidos.

Um resumo da composição das argamassas de revestimento produzidas encontra-se na Tabela 4. Busca-se uma trabalhabilidade usual e aplicável na prática, igual para todos os traços de argamassas, controlada pelo ensaio de flowtable com valores de $245 \pm 5 \mathrm{~mm}$. A quantidade de cimento e de agregado miúdo em cada traço foi constante, para diferentes relações água/cimento e relações água/ligante (cimento + cal hidratada). Tal variação justifica-se pelo fato de que cada traço apresenta volume de materiais secos diferentes, especialmente à quantidade de cal, o que influencia na obtenção da consistência.

Tabela 4: Composição das argamassas de revestimento.

\begin{tabular}{|c|c|c|c|c|c|c|c|c|}
\hline Sigla & Traço & $\begin{array}{c}\text { Cimento } \\
(\mathrm{g})\end{array}$ & $\begin{array}{c}\text { Cal } \\
(\mathrm{g})\end{array}$ & $\begin{array}{c}\text { Areia fina } \\
(\mathrm{g})\end{array}$ & $\begin{array}{c}\text { Areia grossa } \\
(\mathrm{g})\end{array}$ & $\begin{array}{c}\text { Água } \\
(\mathrm{g})\end{array}$ & w/c & Água/ligante \\
\hline TR1 & $1: 0: 6$ & 327,68 & 0 & $1.198,50$ & $1.493,40$ & 300,00 & 0,92 & 1,41 \\
\hline TR2 & $1: 0,5: 6$ & 327,68 & 89,62 & $1.198,50$ & $1.493,40$ & 310,00 & 0,95 & 1,06 \\
\hline TR3 & $1: 1: 6$ & 327,68 & 179,22 & $1.198,50$ & $1.493,40$ & 320,00 & 0,98 & 0,86 \\
\hline TR4 & $1: 1,5: 6$ & 327,68 & 268,85 & $1.198,50$ & $1.493,40$ & 325,00 & 0,99 & 0,72 \\
\hline
\end{tabular}

Fonte: Autores.

\subsection{Ensaio de mesa de consistência (flowtable)}

Os ensaios de mesa de consistência (flowtable) realizados nas misturas de argamassas seguem as prescrições da NBR 13276 (ABNT, 2016). A quantidade de água utilizada em cada traço é controlada pelo índice de consistência da argamassa dos traços ensaiados. De acordo com Sousa \& Aquino Filho (2013), a consistência da argamassa deve ser constante ao se comparar diferentes traços para os ensaios de cisalhamento direto.

Os valores da densidade de massa das argamassas no estado fresco são $1,96 \mathrm{~g} / \mathrm{cm}^{3}, 2,19 \mathrm{~g} / \mathrm{cm}^{3}, 2,15 \mathrm{~g} / \mathrm{cm}^{3}$ e 2,12 $\mathrm{g} / \mathrm{cm}^{3}$ para os traços TR1, TR2, TR3 e TR4, respectivamente. O traço TR1 classifica-se como argamassa D5 (valores entre 1,80 e 2,20 g/ $\mathrm{cm}^{3}$ ), enquanto os demais traços como D6 (maior que 2,00 g/ $\mathrm{cm}^{3}$ ), conforme NBR 13281 (ABNT, 2005). Nos traços TR2, TR3 e TR4 a densidade em massa é reduzida com o aumento do teor de cal, o qual preenche os vazios. Por outro lado, a porosidade sofre aumento decorrente do acréscimo do volume de água em suas dosagens.

\subsection{Ensaio de cisalhamento direto}

Após o ensaio de flowtable os traços de argamassa são submetidos ao ensaio de cisalhamento direto, conforme procedimentos da D3080 (ASTM, 2011). A moldagem das argamassas é feita em uma caixa de cisalhamento bipartida (lado de $100 \mathrm{~mm}$ e altura de $40 \mathrm{~mm}$ ), Figura 2. O tempo entre a fase de consolidação e o início do cisalhamento é de 10 min. Durante os ensaios foram adotadas baixas tensões normais, a fim de se evitar a exsudação em excesso da pasta, o que descaracterizaria a 
veracidade dos resultados, visto que neste trabalho os valores de tensão mais elevados geram resultados não representativos se comparados aos encontrados na prática.

Após a consolidação, foi iniciado o processo de cisalhamento, com uma velocidade constante de $0,2 \mathrm{~mm} / \mathrm{s}$, e medida a força cisalhante por meio de um anel de carga. A velocidade adotada teve como objetivo impedir que a água presente no traço de argamassa não fosse drenada antes do final do ensaio, permanecendo na caixa bipartida durante todo o processo, e também por se tratar de uma velocidade em que os fenômenos ocorrem em situações práticas. Velocidades acima de 0,1 mm/s não refletem a realidade encontrada na prática, além de favorecem a separação de fases das argamassas em seu estado fresco (Cardoso, John \& Pileggi, 2009).

O ensaio de cisalhamento direto é empregado especificamente para gerar parâmetros de tensão de cisalhamento, coesão e ângulo de atrito. O equipamento utilizado é acoplado a um software que gera gráficos de tensões cisalhantes versus deslocamento, para cada tensão normal aplicada. Por meio de regressão linear, originada pelas envoltórias de resistência de cada tensão máxima cisalhante e das tensões normais, segundo os critérios de Mohr-Coulomb, são obtidos os valores da coesão e do ângulo de atrito. A coesão é dada pela interceptação da reta na ordenada da tensão cisalhante quando a tensão normal for nula e o ângulo de atrito originado da inclinação da reta gerada pelos critérios de Mohr-Coulomb.

Figura 2: moldagem da argamassa para o ensaio de cisalhamento direto: argamassa dentro da caixa de cisalhamento (a), moldagem da argamassa (b) e corpo de prova após ensaio (c).
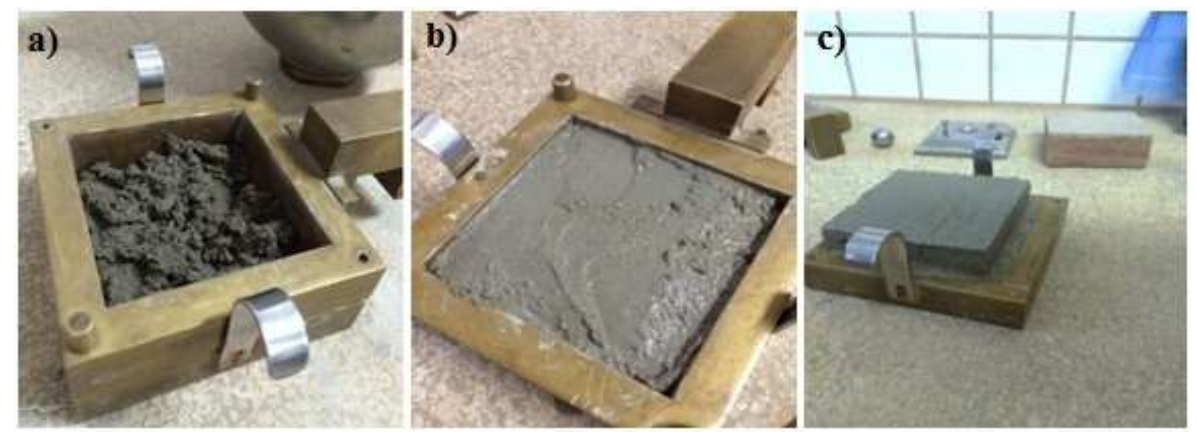

Fonte: Autores.

Cada dosagem (TR1, TR2, TR3 e TR4) foi submetida as tensões normais de $10 \mathrm{kPa}, 37 \mathrm{kPa}$ e $50 \mathrm{kPa}$, totalizando 12 ensaios de cisalhamento direto. Valores próximos das tensões normais ensaiadas foram encontrados na literatura (Lu, Wang \& Rudolphi, 2007; Lu \& Wang, 2011; Araújo, et al., 2017; Sousa \& Aquino filho, 2013). Como o tempo total de cada ensaio é de aproximadamente 50 min., para cada tensão normal aplicada, as propriedades das argamassas poderiam ser alteradas, influenciando na sua trabalhabilidade. Assim, para não descaracterizar os resultados do ensaio de cisalhamento direto, cada traço dosado foi utilizado em apenas um corpo de prova.

Após a dosagem dos traços, a quantidade de argamassa produzida foi utilizada para duas finalidades, uma parte para moldagem e execução do ensaio de cisalhamento direto (amostras em estado fresco) e outra para ser moldada em estado endurecido para realização de ensaio de resistência à compressão simples, segundo a NBR 7215 (ABNT, 2019). Posteriormente, ensaios de Microscopia Eletrônica de Varredura (MEV) foram conduzidos nas amostras de argamassa de revestimento no estado endurecido, para todos os traços investigados, após 28 dias de sua moldagem, com o intuito de observar a existência de mudanças na estrutura à medida que a proporção da aglomerante é aumentada. 


\subsection{Ensaio de resistência à compressão simples}

Para o ensaio de resistência à compressão simples foram utilizados moldes cilíndricos, com 10 mm de diâmetro e 100 mm de altura, segundo a NBR 7215 (ABNT, 2019). Foram moldados 24 corpos-de-prova, submetidos à cura ao ar livre após $48 \mathrm{~h}$, com temperatura ambiente de $26^{\circ} \mathrm{C}$, durante 7, 14 e 28 dias. Para o rompimento dos corpos de prova de argamassa, utilizou-se uma prensa EMIC, com capacidade máxima de $300 \mathrm{KN}$ e dotada de software Tesc para determinação dos dados.

\subsection{Ensaio de microscopia eletrônica de varredura}

O ensaio de Microscopia Eletrônica de Varredura (MEV) foi realizado nas amostras de argamassa de revestimento, para cada traço, a fim de observar mudanças na sua estrutura em função da adição de cal. As amostras foram retiradas da região interna dos corpos-de-prova provenientes dos ensaios de resistência à compressão simples (Figura 3-a), expostas ao ar livre durante um período de 28 dias e preparadas de forma a apresentar superfície laminar (Figura 3-b), com comprimento máximo de $20 \mathrm{~mm}$ e espessura máxima de $7 \mathrm{~mm}$. Após a preparação, as amostras são metalizadas com grafite durante um período de 15 min (Figuras 3-c-d) e submetidas à análise microscópica de varredura, utilizando-se o equipamento JEOL JSM 6400, acoplado a um microscópio, com capacidade para ampliação de imagens até 300.000 vezes.

Figura 3: Etapas de preparação das amostras para o ensaio de MEV: fragmentos dos corpos de prova (a), fixação das amostras em base metálica (b), equipamento de metalização (c) e amostras metalizadas (d).
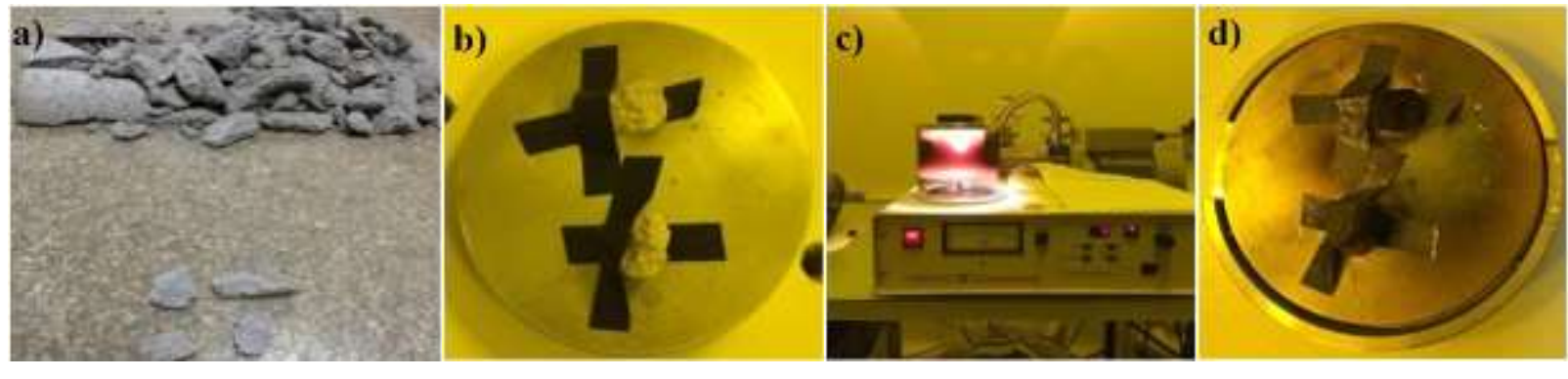

Fonte: Autores.

\section{Resultados}

São apresentados os resultados dos ensaios de cisalhamento direto das argamassas de revestimento no estado fresco, resistência à compressão simples e análise microestrutural para o estado endurecido.

\subsection{Resistência ao cisalhamento das argamassas em estado fresco}

As curvas de tensão cisalhante versus deslocamento horizontal das argamassas em diferentes traços e tensões normais encontram-se na Figura 4. Todas as curvas apresentam um comportamento de pico e após atingir o valor máximo de tensão cisalhante decrescem com o aumento do deslocamento horizontal. As tensões cisalhantes estabilizam próximo de $9 \mathrm{~mm}$ de deslocamento, sendo esta definida como a tensão residual, com exceção das curvas das tensões normais de 37 e 50 kPa para o traço TR3, que ainda apresentam uma tendência de decréscimo no limite de deslocamento do ensaio. 
Figura 4: Curvas de tensão cisalhante versus deslocamento horizontal para cada traço: TR1 (a), TR2 (b), TR3 (c) e TR4 (d).

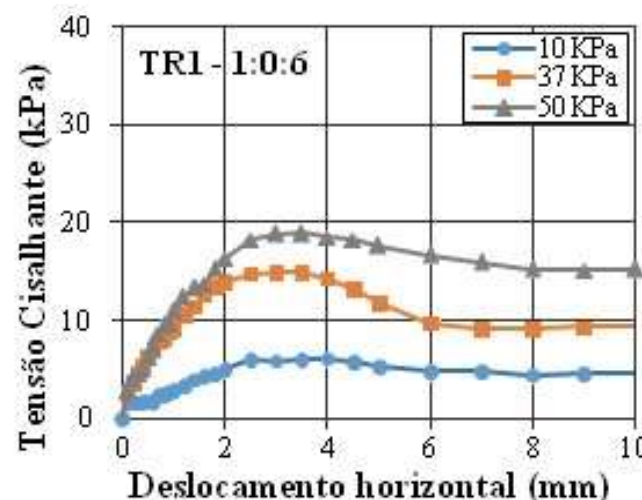

(a)

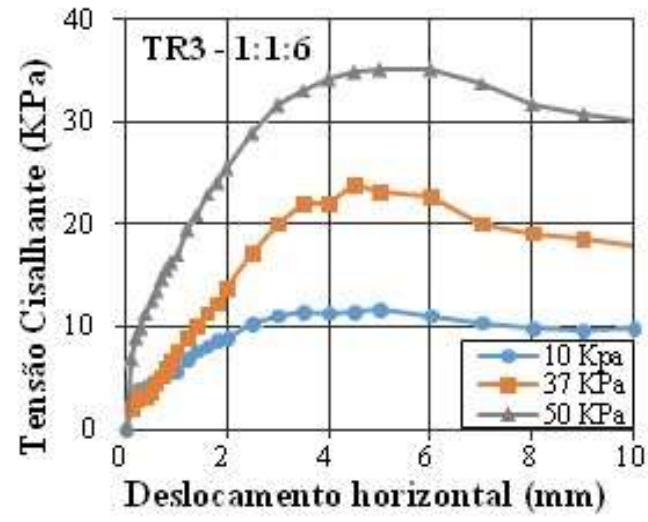

(c)

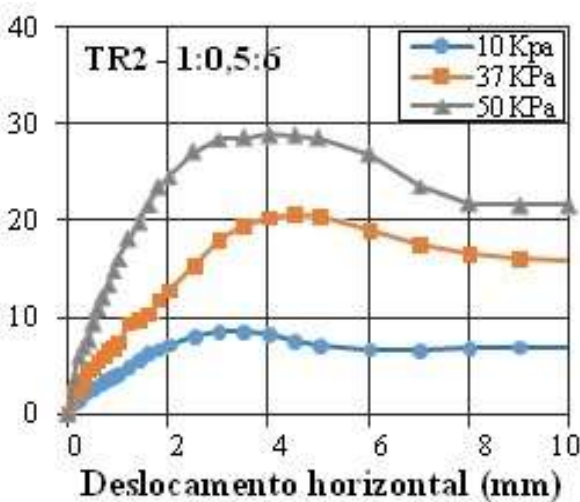

(b)

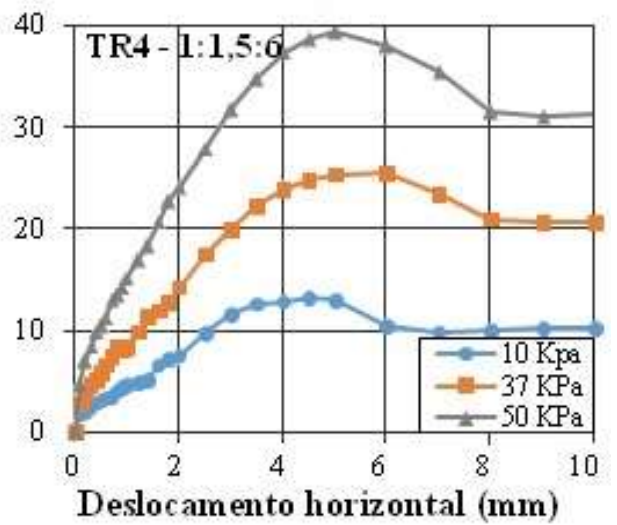

(d)

Fonte: Autores.

A deformação correspondente à tensão cisalhante máxima aumenta com o acréscimo da tensão normal para um mesmo teor de cal adicionado e também com o acréscimo do teor de cal, indicando que quanto maior o teor de cal, melhor torna-se a trabalhabilidade. Logo, o ensaio de cisalhamento direto permite avaliar os fatores que influenciam a trabalhabilidade das argamassas.

As curvas de tensão cisalhante versus deslocamento horizontal para a mesma tensão normal aplicada e diferentes traços, Figura 5, mostra que as deformações correspondentes às tensões cisalhantes máximas crescem com o aumento da tensão normal e com o acréscimo do teor de cal ao traço. Tal comportamento foi similar ao apresentado por Campos et al. (2015). 
Figura 5: Curvas de tensão cisalhante versus deslocamento horizontal para as tensões normais de $10 \mathrm{kPa}(\mathrm{a}), 37 \mathrm{kPa}$ (b) e 50 $\mathrm{kPa}(\mathrm{c})$.

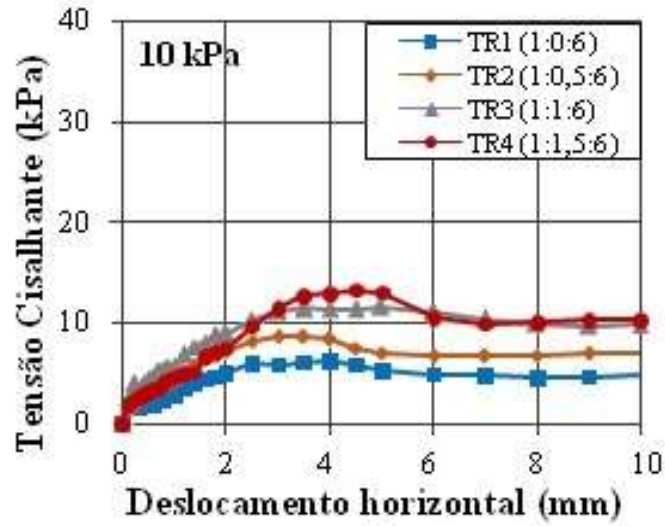

(a)

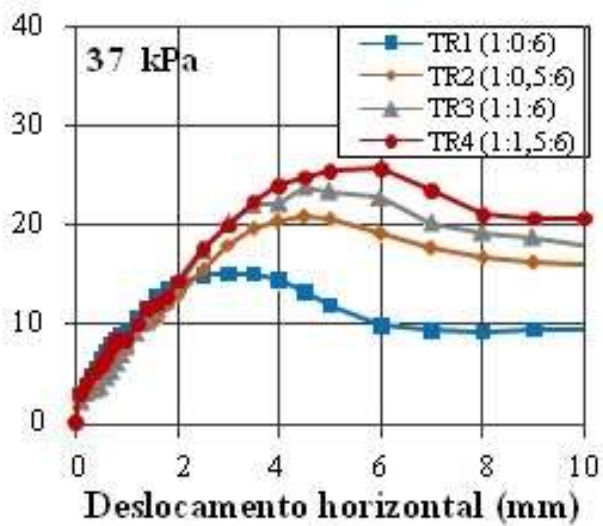

(b)

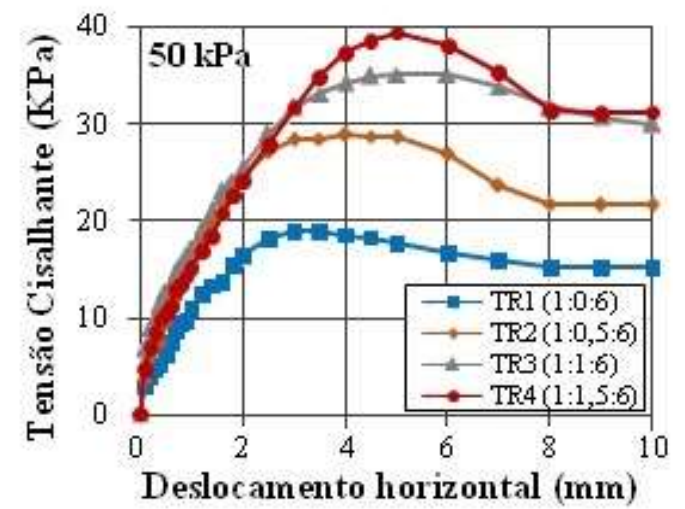

(c)

Fonte: Autores.

\subsection{Resistência à compressão simples}

Os valores da Resistência à Compressão Simples (RCS) das argamassas, considerando as variações do tempo de cura e diferentes traços, são mostrados na Figura 6. A argamassa TR3 (1:1:6), considerada o traço de referência por ser o mais utilizado na prática e observado no estado da arte, apresenta valores de RCS decrescentes com o tempo de cura, atingindo 9,4 MPa aos 7 dias e 4,9 MPa aos 28 dias. De forma semelhante, Campos, et al. (2015) obtiveram valor de RCS igual a 4,1 MPa, para o mesmo traço aos 28 dias, utilizando cimento CP II-F-32 e cal CH-I. Já Carasek (2010), nas mesmas condições de traço e cura, com cimento CP II-F-32 e cal CH-I, obteve o valor de 7,2 MPa aos 28 dias, sendo superior ao desta pesquisa.

A argamassa TR1 mostra um crescimento discreto nos valores de RCS, enquanto que a TR2 apresenta um pico aos 14 dias (8,9 MPa), que decresce aos 28 dias (7,0 MPa). No traço TR4 o valor da RCS apresenta um acréscimo entre 7 e 14 dias de cura, mas reduz aos 28 dias, chegando ao valor de 3,6 MPa. 
Figura 6: Variação da RCS com o tempo de cura (a) e com o tipo de traço (b).

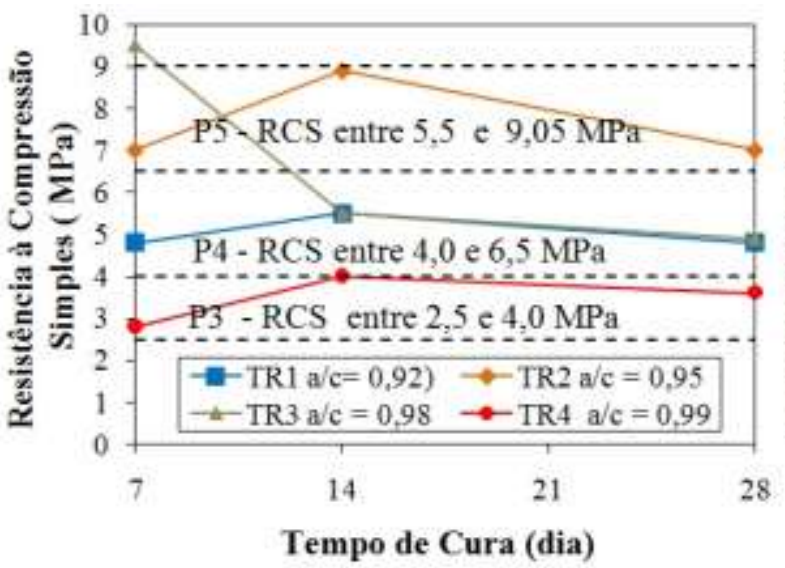

(a)

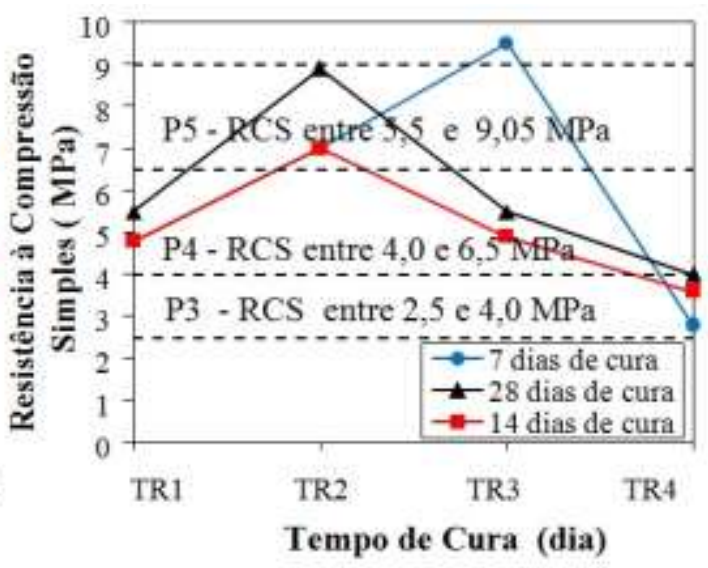

(b)

Fonte: Autores.

\subsection{Análise microestrutural}

As eletromicrografias das argamassas após 28 dias de cura e com ampliação de 500x são mostradas na Figura 7. A Microscopia Eletrônica de Varredura (MEV) fornece informações sobre a morfologia e identificação dos poros, arranjo entre os constituintes e rugosidade das superfícies. O método também permite analisar a zona de interface entre materiais, identificar os cristais presentes na pasta-ligante, caracterizar os agregados (forma, textura, tamanho, quantidade e superfície de corte) e caracterizar uma estrutura porosa (tipo de poros, tamanho, forma, localização, interligação e profundidade).

Figura 7: Eletromicrografias das argamassas no estado endurecido após 28 dias de cura com ampliação de 500x para os traços TR 1 (a), TR 2 (b), TR 3 (c) e TR 4 (d).

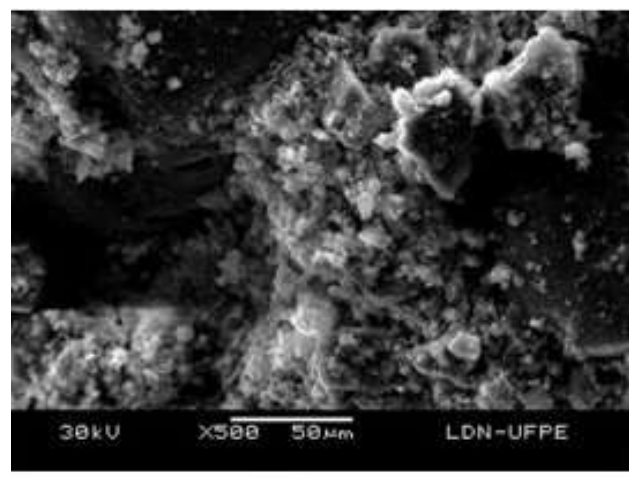

(a)

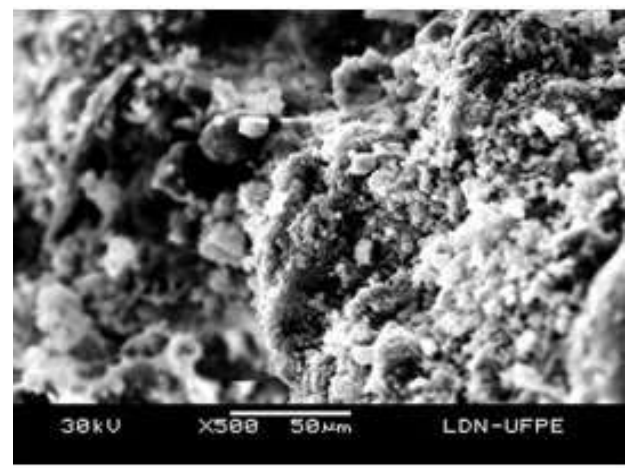

(c)

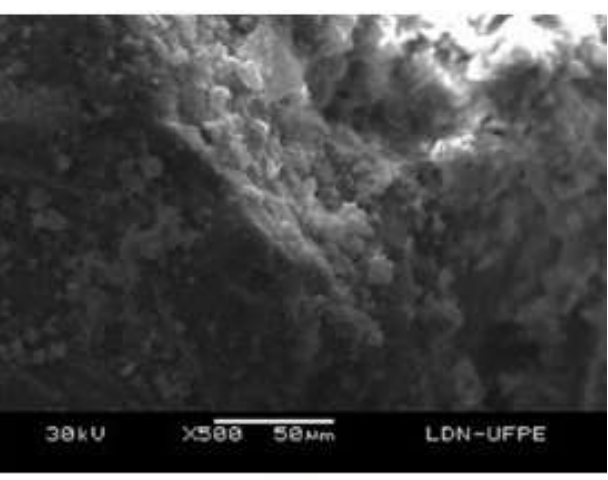

(b)

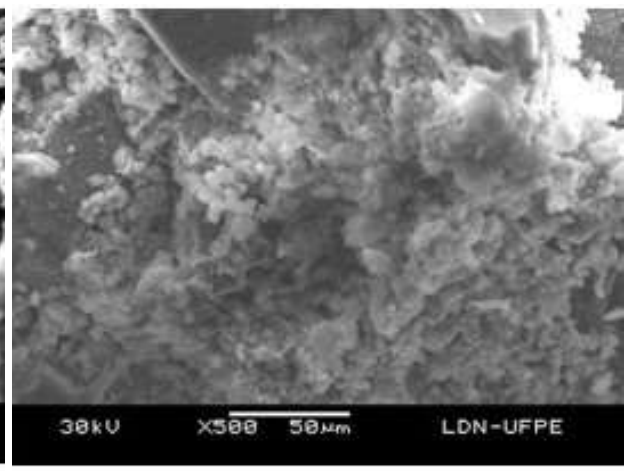

(d)

Fonte: Autores. 


\section{Discussão}

É analisada a influência da adição da cal no comportamento das argamassas no estado fresco, por meio do ensaio de cisalhamento direto, e no estado endurecido pelo ensaio de compressão simples e pela análise microestrutural.

\subsection{Comportamento das argamassas no estado fresco}

As envoltórias de resistência ao cisalhamento das argamassas, com base no critério de ruptura de Morh-Coulomb para as tensões cisalhantes máximas e para as tensões cisalhantes correspondentes a $10 \%$ de deformações, obtidas a partir dos ensaios de cisalhamento direto, são apresentadas na Figura 8.

Figura 8: Envoltórias de resistência (a) e tensão cisalhante por traço para a tensão máxima (b); envoltórias de resistência (c) e tensão cisalhante por traço para a tensão correspondente a $10 \%$ de deformação (d).

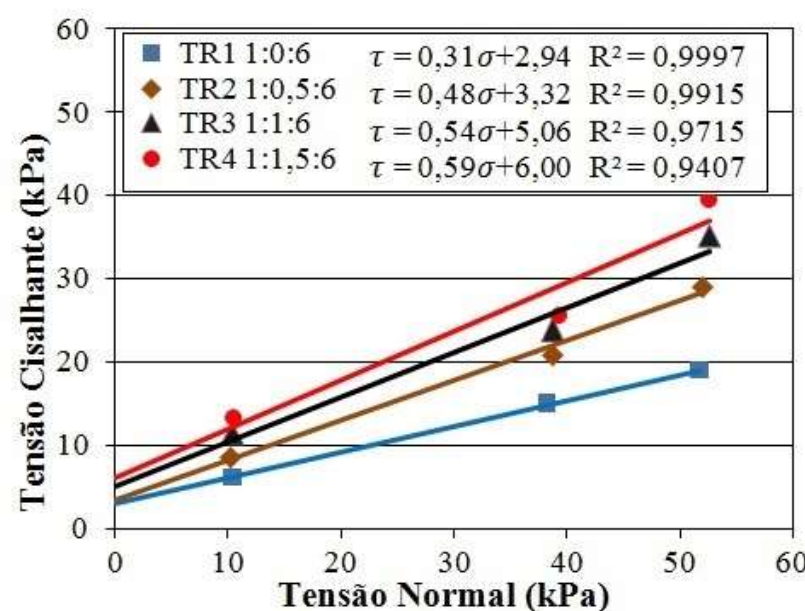

(a)

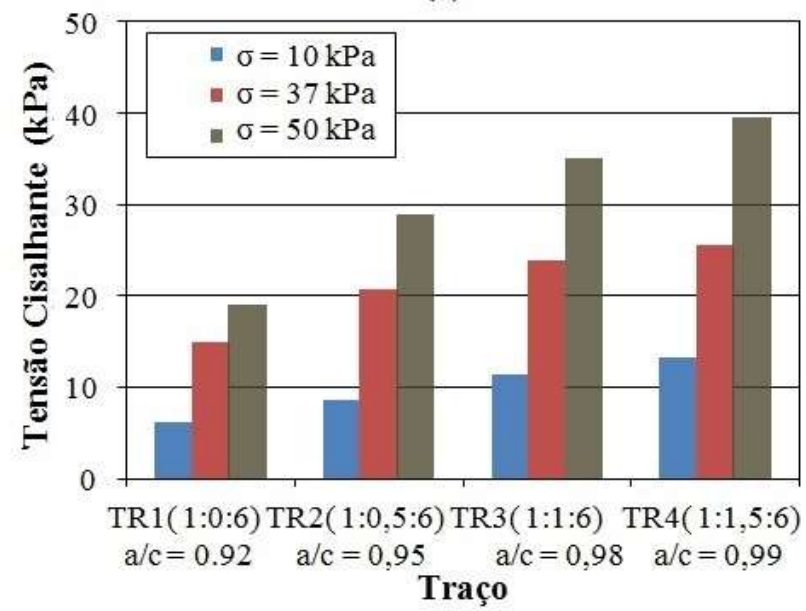

(c)

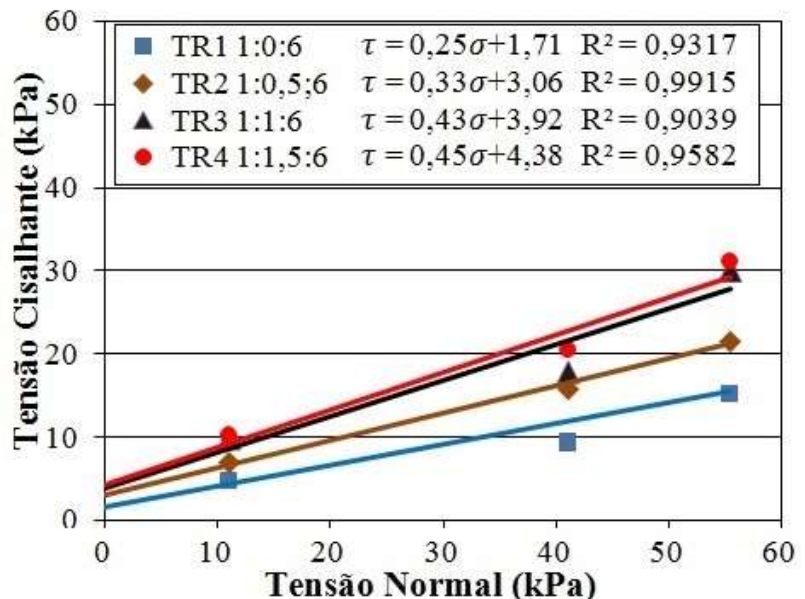

(b)

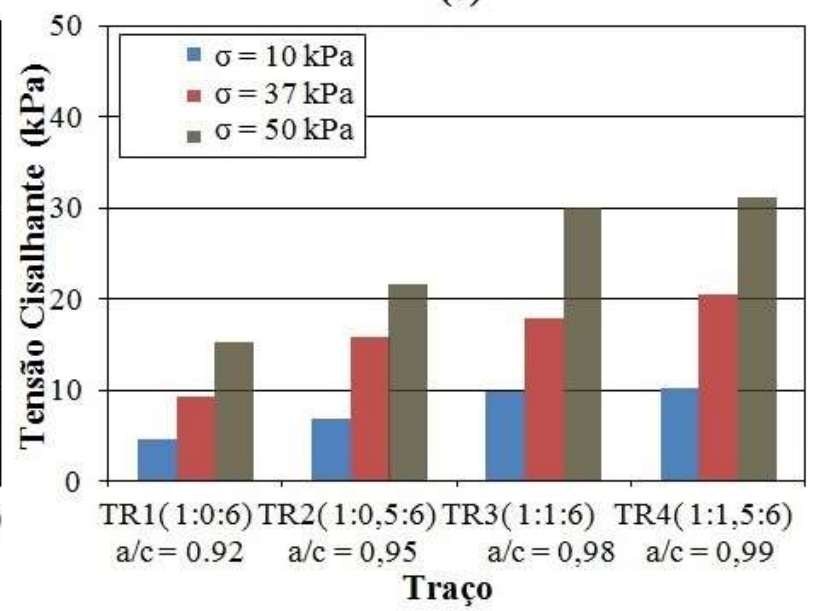

(d)

Fonte: Autores.

Os valores da coesão (c) e do ângulo de atrito (Ø), correspondentes a inclinação da envoltória de resistência para a tensão cisalhante máxima e para a tensão cisalhante relativa à deformação de $10 \%$, encontram-se na Tabela 5 . Os valores foram obtidos por regressão linear com coeficientes de correlações superiores a 0,90. Para um mesmo traço de argamassa, os valores de coesão e ângulo de atrito, correspondentes a tensão cisalhante máxima são superiores aos valores para a deformação de $10 \%$, indicando que ao lançar a argamassa de revestimento o esforço do operador diminui à medida que faz o espalhamento. 
O acréscimo de cal na composição das argamassas eleva os valores da coesão e do ângulo de atrito. Tanto o atrito interno quanto a coesão de uma argamassa dependem da distância entre as partículas que constituem a argamassa, fazendo com que uma mistura com maior quantidade de cal em seu traço, proporcione uma menor distância entre os grãos, dificultando o cisalhamento entre as camadas e, consequentemente, apresente um maior ângulo de atrito e aumente a coesão da pasta (Sousa, 2005; Lu \& Wang, 2011).

Tabela 5: Valores de coesão e ângulo de atrito.

\begin{tabular}{|l|c|c|c|c|}
\hline \multirow{2}{*}{ Traço } & \multicolumn{2}{|c|}{ Coesão $(\mathrm{kPa})$} & \multicolumn{2}{c|}{ Ângulo de atrito $\left(^{\circ}\right)$} \\
\cline { 2 - 5 } & Tensão de Pico & $\begin{array}{c}\text { Deformação } \\
\text { de } 10 \%\end{array}$ & Tensão de Pico & $\begin{array}{c}\text { Deformação } \\
\text { de } 10 \%\end{array}$ \\
\hline TR1 - 1:0:6 & 2,94 & 1,71 & 18 & 14 \\
\hline TR2 - 1:0,5:6 & 3,32 & 3,06 & 25 & 18 \\
\hline TR3 - 1:1:6 & 5,06 & 3,92 & 28 & 23 \\
\hline TR\$ - 1:1,5:6 & 6,00 & 4,38 & 30 & 24 \\
\hline
\end{tabular}

Fonte: Autores.

Uma das principais funções exercidas pela cal numa argamassa mista é auxiliar na trabalhabilidade, indiretamente medida a partir do atrito entre os grãos dos agregados e da coesão da mistura. $\mathrm{O}$ incremento na quantidade de cal presente nos traços TR2, TR3 e TR4 resulta no acréscimo gradativo da coesão e ângulo de atrito às respectivas misturas, Figura 8.

Embora não exista na literatura valores de coesão, ângulo de atrito, tensões cisalhantes ou deslocamento horizontal que atestem uma boa trabalhabilidade da argamassa (Lu, Wang \& Rudolphi, 2007), a avaliação comparativa desses parâmetros entre os diferentes traços, juntamente com a análise em campo das argamassas, pode auxiliar na compreensão do seu comportamento reológico, servindo inclusive como base para a definição de eventuais valores que permitam classificar as misturas quanto a sua facilidade de espalhamento na base.

Os baixos valores de coesão do traço sem cal (TR1), por exemplo, indicam a dificuldade em se preencher toda a área de contato da argamassa com a base, atestando a assertividade na recomendação pelo uso da cal hidratada nas argamassas mistas, a fim de obter uma melhor união entre os grãos. Dentre as amostras com a cal, há uma semelhança nos valores de coesão dos traços TR3 e TR4, estando bem acima dos valores encontrados para o TR1 (sem cal) e o TR2. Esse cenário indica a adequação das misturas com proporções de 1:1:6 (TR3) e 1:1,5:6 (TR4), normalmente empregados em usos para ambientes externos.

\subsection{Comportamento das argamassas no estado endurecido}

A resistência à compressão simples do traço TR3 (1:1:6 - referência) obtida aos 28 dias de cura é 4,9 MPa, sendo um valor muito próximo ao do traço TR1 (1:0:6) aos 14 dias. Para o TR3 com cal, a resistência apresenta redução com o tempo de cura, principalmente entre 7 e 28 dias, cuja queda é próxima de 26\%. No traço TR2 (1:0,5:6) a RCS aos 7 dias é 7,0 MPa, correspondendo a um acréscimo de $46 \%$ se comparado à argamassa de referência, e aos 14 dias atingiu o valor máximo $(8,9$ $\mathrm{MPa})$.

Os valores médios de RCS aos 28 dias são 5,5 MPa, 7,0 MPa, 4,9 MPa e 3,6 MPa, respectivamente para os traços TR1, TR2, TR3 e TR4, sendo as argamassas classificadas como P3 (TR4), P4 (TR1 e TR3) e P5 (TR2), segundo a NBR 13281 (ABNT, 2005). As argamassas TR1 e TR3, classificadas como P4, são consideradas adequadas para aplicações em revestimentos, pois possuem uma capacidade maior de deformação. A argamassa TR2, enquadrada como P5, atesta uma maior 
rigidez e resistência à argamassa em seu estado endurecido, além de ser mais propícia ao aparecimento de patologias, como por exemplo, fissuras em revestimentos. A argamassa TR4 classificada como P3, é considerada uma argamassa menos resistente quando comparada às demais argamassas ensaiadas, visto a seu menor RCS aos 28 dias.

O acréscimo da cal no TR4 em relação ao TR1 foi de 1,5 (em volume), ocasionando uma maior quantidade de aglomerante de cal na dosagem do traço. De acordo com Cincotto, et al. (1985), quando se utiliza pequenas quantidades da cal, que proporcionem um equilíbrio entre os traços, variando essa quantidade entre 0,25 e 1 (em volume), a cal auxilia no ganho de resistência.

A RCS aos 28 dias da argamassa TR1 é maior em 53\%, quando comparado com a argamassa do traço TR4, justificado pela ausência da aglomerante cal. Embora a aglomerante seja responsável pelo ganho de resistência, a quantidade de água cresce à medida que se adiciona a cal. Assim, aos 28 dias, há redução das resistências das argamassas TR2 em relação a TR3 em 43\% e da TR3 em relação a TR4 de 36\%.

A adição de cal ao traço eleva o fator água/cimento para uma mesma trabalhabilidade nas argamassas no estado fresco, mas no estado endurecido pode aumentar a porosidade, conferindo possíveis causas de perda de RCS. Comportamento similar foi observado por Allen \& Iano (2013) ao avaliarem o desempenho de argamassas mistas, verificando que a maior quantidade da cal nas dosagens promove perda de resistência à compressão simples e à tração nas argamassas no estado endurecido aos 28 dias, enquanto que no estado fresco, as argamassas têm ganho trabalhabilidade, plasticidade, elasticidade e retenção de água.

Há um aumento da coesão e do ângulo de atrito para os diferentes traços, Figura 9-a, tanto na tensão de pico quanto nas tensões correspondentes a 10\% de deformação. O RCS aos 28 dias de cura sofre uma redução com o acréscimo do teor de cal, Figura 9-b. O acréscimo da quantidade de cimento no traço eleva a resistência mecânica da argamassa, no entanto, ao se tratar do acréscimo de cal hidráulica e cal aérea, o comportamento é o oposto, pois quanto maior a quantidade de cal, maior é a porosidade da argamassa (2011). Assim, na dosagem das argamassas mistas busca-se encontrar o ponto de equilíbrio da adição da cal.

Figura 9: Variação da coesão e ângulo de atrito no estado fresco com o tipo de traço de argamassa (a) e variação da coesão no estrado fresco e RCS no estado endurecido com o tipo de traço de argamassa (b).

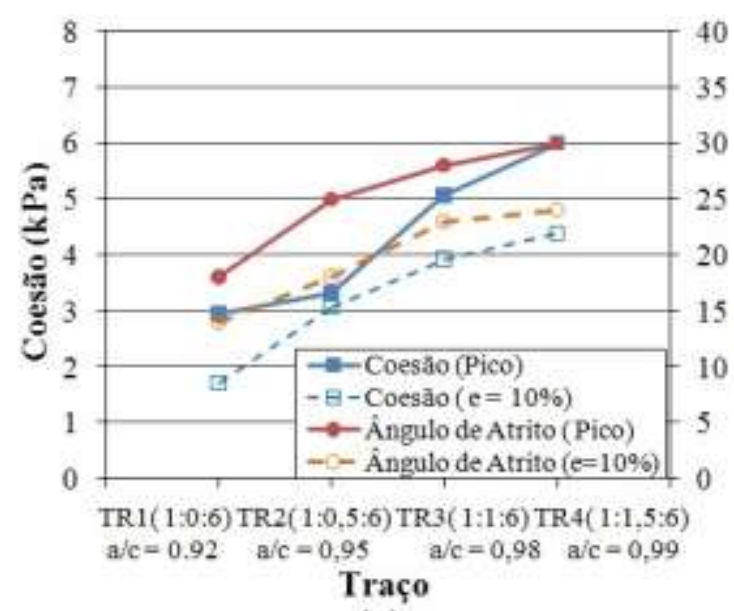

(a)

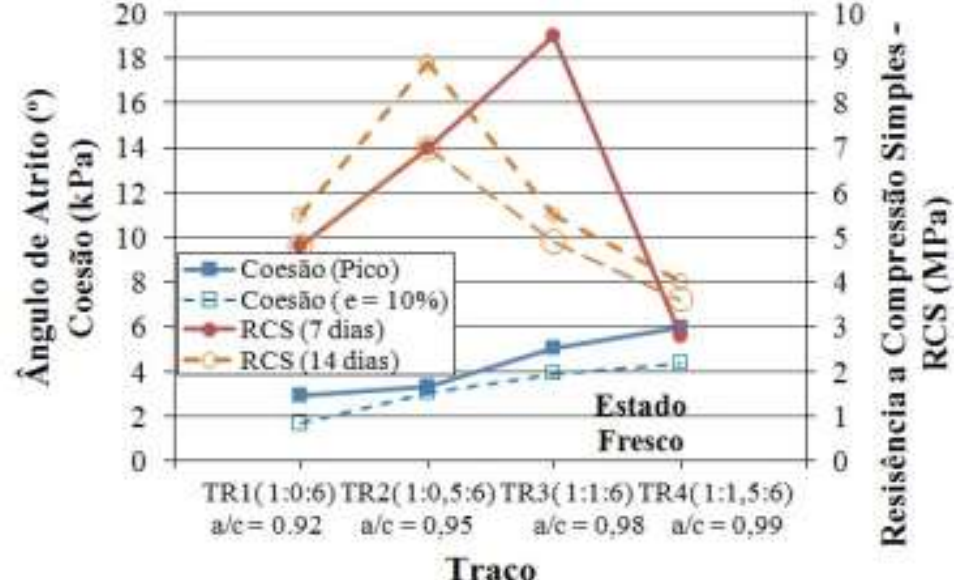

Traço

Fonte: Autores.

A eletromicrografia da argamassa TR1 no estado endurecido, Figura 7-a, mostra uma intensa aderência entre os agregados de forma angular e subangular com a pasta de cimento, sendo observada a sinalização de cristal, resultado do 
endurecimento da pasta. $\mathrm{O}$ traço sem a presença da aglomerante cal (TR1) foi dosado com uma menor quantidade de água do que nos demais traços, apresentando assim baixa porosidade e poros de formas mais alongadas, o que atesta sua maior resistência à compressão em relação ao TR4, que por sua vez foi dosado com maior quantidade de água e apresenta poros mais arredondados.

Na análise microestrutural do TR2, Figura 7-b, há uma melhor aderência entre a pasta e os agregados, justificado pela presença da cal em sua dosagem. Os agregados (areias fina e grossa) presentes no traço apresentam uma superfície rugosa, ocorrendo uma penetração da pasta de cimento no interior do agregado. Dessa forma, a coesão dos materiais que compõe o TR2 é aumentada. Esta característica corrobora com os resultados da coesão e do ângulo de atrito obtidos no ensaio de cisalhamento direto, em que o TR2 se apresenta mais coeso do que o TR1 e com um maior ângulo de atrito. Tal comportamento também foi observado por Gominho (2016).

Observa-se a presença da aglomerante cal em maior quantidade e a união entre os aglomerantes e os agregados presentes na dosagem do TR3, Figura 7-c, atestando um maior entrosamento entre os constituintes da argamassa. Os agregados com superfícies de contato rugosas apresentam maior aderência entre eles e a pasta-ligante, devido à penetração da mesma em suas reentrâncias, além de promoverem o crescimento de cristais acirculares e tubulares.

No traço TR4 há uma grande quantidade de poros, Figura 7-d, contribuindo diretamente na perda de resistência da argamassa de revestimento aos 28 dias. Há uma maior contribuição da quantidade da cal, fazendo a ligação entre os aglomerantes utilizados nos traços (cimento e cal). No interior da amostra, a porosidade é elevada devido à sua estrutura celular, com poros bem definidos (alveolares) sem interligação entre eles e com contornos mais irregulares.

\section{Conclusão}

Novas metodologias e ferramentas de avaliações das argamassas no estado fresco são necessárias para que se aumente a robustez do produto argamassa, visando maior produtividade e desempenho. $\mathrm{O}$ método do ensaio de cisalhamento direto apresenta sensibilidade para avaliação do comportamento da argamassa em estado fresco, obtendo parâmetros que permitem distinguir de forma mais eficaz as diferenças não perceptíveis em equipamento de análise monoponto, como o caso do flowtable.

Os índices obtidos no ensaio de cisalhamento direto (coesão, ângulo de atrito, tensão cisalhante e deslocamento horizontal de ruptura) se mostram crescentes à medida que se incrementa o teor da cal na dosagem das argamassas. Com tal método se pode evidenciar que uso da cal hidratada nas argamassas proporciona maior interação das partículas, facilitando o seu espalhamento na base.

As resistências à compressão simples das argamassas, em seu estado endurecido, para todos os traços analisados, se enquadram dentro dos limites normativos e atestam argamassas de boa qualidade e aptas para utilização em revestimentos. $\mathrm{O}$ traço TR3 foi classificado como uma argamassa P4, embora apresente valores de resistência inferiores à classificação P5. A argamassa TR3 é considerada a mais adequada para o uso de revestimentos, devido à sua maior capacidade de deformação, sendo menos propícia ao aparecimento de patologias como fissuras.

A adição da aglomerante cal na dosagem dos traços aumentou a porosidade nas amostras de argamassa, promovendo perda de resistência à compressão, uma maior aderência entre os materiais utilizados nos traços, formando flóculos entre eles e elevação da hidratação do cimento, favorecendo a sua cristalização.

Em pesquisas futuras pode-se considerar a utilização de diferentes tipos de cales nos traços estudados, tendo como fator de influência a qualidade da cal e utilizar na prática as dosagens dos traços de argamassa ensaiados, avaliando a trabalhabilidade e rendimento das argamassas em canteiros de obras. 


\section{Agradecimentos}

Os autores agradecem ao Programa de Pós-Graduação em Engenharia Civil e aos Laboratórios de Materiais de Construção Civil (LMCC) da Universidade de Pernambuco (UPE), Análises Químicas (LAQ) da Universidade Católica de Pernambuco (UNICAP), de Dispositivos de Nanoestruturas (LDN) da Universidade Federal de Pernambuco (UFPE) e de Solos e Instrumentação (LSI) da Universidade Federal de Pernambuco.

\section{Referências}

Allen, E., \& Iano, J. (2013). Fundamentos da Engenharia de Edificações. (5a ed.). Bookman.

Almeida, R. S., Silva, F. G. S., Silva, V. S., \& Gonçalves, J. P. (2013). Avaliação da resistência ao cisalhamento em argamassa à base de cimento. Cesumar, $15(1), 5-11$.

American Society for Testing and Materials - ASTM (2011). ASTM 3080: Standard test method for direct shear test of soils under consolidated drained conditions. USA.

Araújo, R. C., Carasek, H., Cascudo, O., \& Angelim, R. (2017). Caracterização reológica de argamassa de revestimento pelo método do cisalhamento direto. In: XII Simpósio Brasileiro de Tecnologia das Argamassas (SBTA). Anais, Brasil.

Associação Brasileira de Normas Técnicas - ABNT (2019). NBR 7215: Cimento Portland - Determinação da resistência à compressão de corpos de prova cilíndricos.

Ball, R. J., Adel, E., \& Allen, G. C. (2011). Influence of carbonation on the load dependent deformation of hydraulic lime mortars. Materials Science and Engineering, 528(7-8), 3193-3199. doi:10.1016/j.msea.2010.12.070.

Campos, M. O. (2014). Estudo da resistência de aderência à tração e ao cisalhamento de revestimentos de argamassa em substratos de concre to. Dissertação de M.Sc., Brasil.

Campos, M. O., Carasek, H., Oliveira, L., Vargas, C. L., \& Costa e Silva, A. J. (2015). Determinação da resistência de aderência ao cisalhamento de revestimentos de argamassa pelo método do cisalhamento direto de solos. In: XI Simpósio Brasileiro de Tecnologia das Argamassas (SBTA). Anais., Brasil.

Carasek, H. (2010). Materiais de Construção Civil e Princípios de Ciência e Engenharia de Materiais. (2a ed.): IBRACON.

Carasek, H., Araújo, R. C., Cascudo, O., \& Angelim, R. (2016). Parâmetros da areia que influenciam a consistência e a densidade de massa das argamassas de revestimento. Revista Matéria, 21(3), 714-732. 10.1590/S1517-707620160003.0068

Cardoso, F. A., John, V. M. \& Pileggi, R. G. (2009). Rheological behavior of mortars under different squeezing rates. Cementand Concrete Research, 39(9), 748-753. 10.1016/j.cemconres.2009.05.014

Cincotto, M. A., Marques, J. C., \& Helene, P. R. L. (1985). Propriedades das argamassas de cimento: cal: areia. In: Seminário sobre argamassas. Anais., Brasil.

Gominho, M. S. L. A. (2016). Caracterização microestrutural de argamassas. Dissertação de Mestrado, Instituto Superior Técnico, Brasil.

Koche, J. C. (2011). Fundamentos de metodologia científica: teoria da ciência e iniciação à pesquisa. Petrópolis: Vozes.

Lu, G., \& Wang, K. (2011). Theoretical and experimental study on shear behavior of fresh mortar. Cement and Concrete Composites, 33(2), 319-327. 10.1016/j.cemconcomp.2010.09.002

Lu, G., Wang, K., \& Rudolphi, T.J. (2007). Modeling rheological behavior of highly flowtable mortar using concepts of particle and fluid mechanics. Cement and Concrete Composites, 30(1), 1-12. 10.1016/j.cemconcomp.2007.06.002

Ludke, M., \& Andre, M. E. D. A. (2013). Pesquisa em educação: abordagens qualitativas: EPU.

NBR 13276(2016).: Argamassa para assentamento e revestimento de paredes e tetos - Determinação do índice de consistência. Rio de Janeiro.

NBR 13281(2005).: Argamassa para assentamento e revestimento de paredes e tetos - Requisitos. Rio de Janeiro.

NBR 16605(2017).: Cimento Portland e outros materiais em pó - Determinação da massa específica, Rio de Janeiro.

NBR 16607(2018).: Cimento Portland - Determinação dos tempos de pega. Rio de Janeiro.

NBR 6473(2003c): Cal virgem e cal hidratada - Análise química. Rio de Janeiro.

NBR 7175(2003d).: Cal hidratada para argamassas - Requisitos. Rio de Janeiro.

NBR 7211(2009b).: Agregados para concreto - Especificação. Rio de Janeiro.

NBR 9289(2000): Cal hidratada para argamassas - Determinação da finura. Rio de Janeiro.

NBR NM 248(2003b): Agregados - Determinação da composição granulométrica. Rio de Janeiro. 
Research, Society and Development, v. 10, n. 1, e17010111617, 2021

(CC BY 4.0) | ISSN 2525-3409 | DOI: http://dx.doi.org/10.33448/rsd-v10i1.11617

NBR NM 45(2006).: Agregados - determinação da massa unitária e do volume de vazios. Rio de Janeiro.

NBR NM 46(2003a): Agregados - Determinação do material fino que passa através da peneira 75 mm, por lavagem. Rio de Janeiro.

NBR NM 52(2009a):: Agregado miúdo - Determinação da massa específica e massa específica aparente. Rio de Janeiro.

Paiva, S. C., Gomes, E. A. O., \& Oliveira, R. A. (2007). Controle de qualidade da cal para argamassas - metodologias alternativas. Revista Ciência \& Tecnologia, 1(1), 1-11.

Pereira, A. S., Shitsuka, D. M., Parreira, F. J., \& Shitsuka, R. (2018). Metodologia da pesquisa científica. (1a ed), Santa Maria: UAB/NTE.

Rubio-Hernández, F. J. (2018). Rheological behavior of fresh cement pastes. Fluids, 3(4), 106-121. 10.3390/fluids3040106

Santos, W. J. (2011). Argamassa de alto desempenho. Dissertação de Mestrado, Universidade Federal Juiz de Fora, Juiz de Fora, Brasil.

Silva, N. G. (2011). Avaliação da retração e da fissuração em revestimento de argamassa na fase plástica. Tese de Doutorado, Universidade Federal de Santa Catarina, Brasil.

Sousa, J. G. G. (2005). Contribuição ao estudo das propriedades das argamassas de revestimento no estado fresco. Tese de Doutorado, Universidade de Brasília, Brasil.

Sousa, J. G. G., \& Aquino Filho, L. P. B. (2013). Caracterização de argamassas no estado fresco aplicando técnica de cisalhamento direto. Evolvere Scientia, $2(1), 68-82$.

Sousa, J. G. G., \& Bauer, E. (2002). Estudo da reologia das argamassas de revestimento no estado fresco. In: Congresso Brasileiro de Engenharia e Ciência dos Materiais (CBECIMAT). Anais. Rio Grande do Norte, Brasil, Nov. 2002, 571-577.

Tokarski, R. B., Matoski, A., Cechin, L., \& Weber, A. M. (2018). Comportamento das argamassas de revestimento no estado fresco, compostas com areia de britagem de rocha calcária e areia natural. Revista Matéria, 23(3), e12196. 10.1590/s1517-707620180003.0530 